Vol. 1, No. 1, Juli 2017, 97-106

Available Online at https://ejournal.warmadewa.ac.id/index.php/kulturistik

DOI: http://dx.doi.org/10.22225/kulturistik.1.1.221

\title{
IDENTIFYING ENGLISH METAPHORS
}

\author{
KetutSudrama \\ Warmadewa University \\ ketut55sudrama@gmail.com
}

\begin{abstract}
A metaphor can be identified in two ways, they are; in a wider sense and a specific sense. This article is only focused on figurative speech in specific sense. In its specific sense it always has three elements, namely: topic, image and the point of similarity. Metaphor then can be classified into two, they are: dead and live metaphors. The aims of this research are: (1) to identify the English metaphors in the English novel, (2) to know the classification of the metaphors, and (3) to identify the structures of metaphors. The data of this research are all collected from an English novel entitled Master of the Game written by Sidney Sheldon (1982) so then the method applied here is of course library research. The theory applied here is proposed by George Lakoff (1979). The result of this research shows that (1) there is always an anomaly meaning in the metaphor, (2) there are two types of metaphors, they are: dead and live, and (3) not all elements of the metaphor are always explicitly stated.
\end{abstract}

Keywords: metaphors, classification, structure

\section{INTRODUCTION}

Words or expressions used in literary works, such as a novel very often have metaphorical meanings. A metaphor is a common figure of speech found in many languages. Metaphor came from the old French metaphore, Latin metaphora, Greek metaphora meaning 'carrying over', 'transfer' (McArthur, 1992). In the wider sense, metaphors are all figures of speech that achieve their effects through comparison, association, and resemblance of meaning. Whereas in a more specific sense, a metaphor is a figure of speech which concisely compares two things by saying that one is the other, rather than one is like the other. Metaphor in a specific sense is almost the same as that of concept of metaphor proposed (Larson, 1984 :271-272). She states that metaphors are grammatical forms which represent two propositions in one semantic structure. The relationship between the two propositions is one of comparison. The comparison is manifested in the comment part of the propositions and the comments are identical, there is some point of similarity. This article only deals with metaphors which contain implied comparison, so the metaphor is discussed by applying the comparison theory.

As the realization of the concept of comparison, metaphors do not have the word 'like' or 'as' as in the case of similes, but they are also comparisons that can often be rewritten as similes.

Example:

- Dewi is an angle

Relation of the examples above classifies Dewi in the first sentence as the topic, something that is being discussed, and angle is the image, that is the thing that the topic is like (Larson, 1984: 273),. As has already been mentioned above that a metaphor is a grammatical form that represents two propositions. Dewiin 
the above sentence is being compared to angle, the thing used to describe the topic figuratively. It means that Dewi has a characteristic similar to that of angle that is 'very beautiful'. The propositions of the metaphor are:

- Dewi is very beautiful.

- Angle is very beautiful

From the proposition above, it is clear that the elements of the above metaphor are Dewi as the topic, angle as the image and very beautiful as the point of the similarity. It can now be clearly identified that the structure of the metaphor consists of three elements, they are: topic, image and point of similarity.

As already has implicitly been stated in the background that sometimes it is difficult to comprehend and identify the structure of the metaphors in literary works. So the aims of this study are:

1. to identify the English metaphors in the English novel,

2. to know the classification of the metaphors

3. to identify the structures of metaphors.

As it has already been mentioned earlier that a metaphor can be considered from both wider and specific sense. If a metaphor is seen from its wider sense, then it will cover all types of figurative speech such as metonymy, synecdoche, personification, hyperbole and so on, but when it is seen from the specific sense, it will concern only one that contains implied comparison.

It its specific sense, a metaphor shows an implied comparison without the aid of such expression as like and as and it always has three elements: topic, image and point of similarity. Look at the example the animal is a crocodile is not metaphorical since it is not figurative. It is simply a true statement and is nonfigurative. If, somewhere, somebody says Anton is a crocodile, it is a real metaphor in which case Anton is being compared to a crocodile with the assumption that there is some common characteristic. Here the topic of the metaphor is Anton, the image is a crocodile but the point of similarity is not explicitly stated. From this example, it can be understood that a metaphor is an expression indicating an implied comparison between a topic being discussed and the image assigned to the topic figuratively.

Metaphor can generally be divided into live and dead metaphors. The meaning of live metaphor cannot be understood only until we know the primary meaning of the words used metaphorically in the comparison (Larson, 1984 :274). For example somebody says Anggi is a block of ice. It is obvious that speaker means something very different from what he actually has uttered. To interpret the utterance, we must be able to analyze what is actually meant by $a$ block of ice, as the image addressed to Anggi, which is technically called the topic of the metaphor. We often have to analyze the meaning in accordance with the context in the whole paragraph or text otherwise we will arrive at a wrong interpretation. After analyzing the whole context, we might conclude that Anggi is a block of ice intended to mean that 'Anggi is unemotional and an unresponsive woman'.

Fraser (in Ortony, $1979: 173$ ) agrees with the idea of a dead metaphor by giving an example of the phrase to kick the bucket. It was once used literally and then metaphorically used to refer to the final struggle of an animal tied by its feet to a beam (which at the time was called a 'bucket'), has now lost any sense of its 
Vol. 1, No. 1, Juli 2017, 99

Available Online at https://ejournal.warmadewa.ac.id/index.php/kulturistik DOI: http://dx.doi.org/10.22225/kulturistik.1.1.221

original source. He then adds that the interpretation of a metaphor requires that the hearer establish an analogy. Indeed, a metaphor is frequently defined as a type of analogy, as an implicit comparison, whereas simile is called an explicit comparison. The first, the speaker announces it although it is seldom mentioned directly. For example, Speaking metaphorically, Ngurah is falling in love, makes it explicit that the utterance should be taken non-literally. The second is by using semantically anomalous sentence. For example, Bram is a gorilla. This sentence is literally meaningless because it cannot be interpreted literally. Consequently, it must be taken metaphorically. The third device is to use a sentence which is pragmatically anomalous. For example, Gung Aji is our priest. This sentence is literally meaningful, but the context of utterance or the real context makes the sentence False or irrelevant because Gung Aji is actually not a priest.

Miller (in Ortony, 1979: 227-240) states that there are three ways that can be taken to comprehend a metaphor, they are: (1) recognition, (2) reconstruction, and (3) interpretation. In the first step, (1) recognition, the reader recognizes that the concept he obtained from the text is different from the known facts about the real world. On this view, the reader realizes that something is false or unrelated to the preceding context, so he re-examines it and then decides that the expression should be a metaphor. The second is reconstruction. Reconstruction of the implied comparison is a critical step in understanding a metaphor. Miller then adds that a metaphor may be regarded as a compressed simile. This reconstruction is a process of forming a metaphor which is derived from a simile. The reconstruction can be done in two ways:

a. A metaphor can be formed by the replacement of 'is like' in simile with 'is'. For example, man is like a wolf can be converted into a metaphor man is a wolf.

$b$. When the comparison is stated in a clause or sentence, however, the simple substitution of 'is' for 'is like' is not always feasible. For example, The crowd rushed through the door like a river bursting to a dam will not admit the simple use of like. We can obtain a metaphor by nominalizing the initial sentence, that is The crowd rushing through the door was a river bursting through a dam.

The third step is interpretation. When the grounds for a comparison are obscure, interpretation becomes crucial. For example, Bram is a gorilla. The reader understands that some properties of gorillas are to be attributed to Bram. The missing properties are understood to be something attributable to both gorillas and man. Therefore, it is necessary to search the text and context for the author's grounds and this research process is one of interpretation.

Whereas Searle states that in metaphorical sentence, what the speaker means differs from what he says (Searle, 1985 :81). In this case, it should be clearly distinguished between speaker's utterance meaning and sentence meaning. When the speaker says something metaphorically, the hearer should think of departing from the literal meaning of the sentence. The speaker's utterance meaning is what the speaker means by uttering words, sentences or expressions. Metaphorical meaning is always the speaker's utterance meaning i.e. the intended meaning which is discoverable only to the reader examining the actual context of the communicative situation. While sentence meaning is what the words, sentences, and expressions semantically mean. The two kinds of meaning should be widely sepa- 
rated.

Lakoff and Johnson then adds that metaphorical concept can also derived from culture (Lakoff, George and Johnson, 1984: 3-6). Let us consider the metaphorical concept 'Time is Money'. From this concept, there are a lot of expressions we can employ:

- You're wasting my time

- I don't have enough time to spare for that

- Thank you for your time

- I lost a lot of time when I got sick

Again the examples above show that in western culture, time is a valuable commodity. Western culture considers that work is typically associated with the time it takes and time is precisely quantified and it is customary to pay people by the hour, week, month, or year. Time is considered to be limited resources. 'Time is money' and 'Time is a valuable commodity' are metaphorical concepts. They are metaphorical since western people utilize their everyday experiences with money, limited resources and valuable commodities to conceptualize time. The essence of the metaphor is understanding and experiencing one kind of thing in terms of another.

Song Guo in the article entitled" Metaphor Studies from the Perspective of Critical Discourse Analysis: A Case Study of Business Acquisition" states that metaphor is cross-domain mapping from the source domain to target domain, with the former typically referring to abstract and intangible concepts and the latter to concrete and tangible ones. It is also added that metaphor is not only a linguistic phenomenon, but also an essential tool with which we come to understand the world (Guo, 2013).

A metaphor is "a figure of speech in which a word or phrase literally denoting one kind of object or idea is used in place of another to suggest a likeness or analogy between them" (in Penninck, 2014). It is then added that the terms focus and frame are indications for the two concepts that are being compared metaphorically by a writer or speaker. The focus is the most essential term and relates to the topic that is being discussed. The frame refers to the other term that is of a different kind of experience from this focus. By bringing together this focus and frame, the metaphor as a rhetorical figure in fact urges the hearer or reader to understand one concept "in terms of" the other concept (Burkholder \& Henry 2009: 98).

Andreas Musolff in the article entitled "SPECIAL FEATURE" The study of metaphor as part of critical discourse analysis states that "metaphor was no longer seen as ephemeral to a theory of meaning but as being 'among our principal vehicles for understanding' our physical, social and inner world by 'mapping' conceptual structures from a relatively familiar, experientially grounded 'source domain' onto a more abstract or less well-known 'target domain' (Musolff, 2012).

\section{METHODS}

All the data of this article were collected from one of the best-selling novels written by Sidney Sheldon entitled Master of the Game published by A Time Warner Company, New York in 1983. There are some personal reasons for choosing this novel, they are: (1) the novel, as stated by the publisher, is one of 
Vol. 1, No. 1, Juli 2017, 101

Available Online at https://ejournal.warmadewa.ac.id/index.php/kulturistik DOI: http://dx.doi.org/10.22225/kulturistik.1.1.221

the best-selling novels of Sidney Sheldon and (2) this novel contains a lot of figurative expressions including metaphors that meet the set requirements.

Since this is library research, the data source was carefully read many times to comprehend as well as to identify the types of metaphors, and to know the structure of the metaphors. The method of collecting data here involved observing the data source in a way proposed (Sudaryanto, 1993 : 133-136). The topic, image, and point of similarity in the metaphors were carefully examined and collected. The collected data were then classified according to their types whether they belong to dead or live metaphors. The topic, image and point of similarity of the metaphors, whether they are implicit or explicit, were analyzed through the context in which they are applied.Since this is qualitative research, the result of the analysis is informally presented in the forms of words and sentences rather than symbols (see (Sudaryanto, 1993 :145). The findings are presented by showing whether the metaphors belong to dead or live and whether all elements of the metaphors are explicitly stated or only implied.

\section{DISCUSSION}

As was stated above that the aims of this study is (1) to identify the metaphors found in the novel, (2) to know the classifications of the metaphors, and (3) to identify the structure of the metaphors. To follow up the aims of this study, there are some steps to do as follows:

Firstly, the sentence suspected of being a metaphor was analyzed in terms of its meaning. If it turned out that the sentence was semantically anomalous so that it was literally unacceptable, by applying the concept of comparison, the data then was classified as a metaphor. To make sure that it is a metaphor, the structure was examined to find out the elements of the metaphors, i.e. topic, image, and point of similarity between the topic and the image. The examination was carried out further to see whether each of them was implicitly or explicitly stated in the comparison.

Secondly, the type of metaphor was identified to see whether it was a dead or alive metaphor. If the comparison was expressed in a fix construction and the meaning could be directly understood without seeking the objects being compared, it was classified as a dead metaphor. Dead metaphors are identified as the idiomatic expressions for they have become frozen structures with fixed meaning. By contrast it was considered to be a live metaphor if the comparison could be understood only after it was discovered what objects were intended to be compared. In a live metaphor they can only be identified by examining the whole context where the comparison is suspected. The discussion was limited only to metaphor of which the elements were clearly identifiable.

1) The store is his bait. That's how he gets new prospectors to come to him. And he grows richer (p. 67).

The sentence 'the store is his bait' cannot be directly understood literally. 'Bait' literally means food or something that looks like food, put on a hook to catch fish or can also mean a person or thing that is used to attract or tempt somebody. From this description, it can be concluded that 'bait' is being figuratively used in this sentence. It means that this sentence must be metaphorical. Considered from the elements of the metaphor, the topic is 'the store' which is referred to 'his bait'. The point of similarity, however, is not explicitly stated. From read- 
Vol. 1, No. 1, Juli 2017, 102

Available Online at https://ejournal.warmadewa.ac.id/index.php/kulturistik DOI: http://dx.doi.org/10.22225/kulturistik.1.1.221

ing the context, it can be inferred that 'the store' and 'the bait' have something in common, both area tool to catch something. 'The store' is to catch prospective customers, and 'the bait' is to catch fish. The metaphor belongs to live metaphors.

2) "This is Brad Rogers," David said. "brad, meet your new boss, Kate McGregor". Brad Rogers held out his hand. "I'm pleased to meet you, Miss McGregor". "Brad is our weapon," David said. "He knows as much about Kruger-Brent, Limited, as I do. If I ever leave, you don't have to worry. Brad will be here" (p. 202).

The sentence 'Brad is our weapon' above cannot be construed literally. It cannot have literal meaning due to its semantic anomaly. ' $\mathrm{Brad}$ ' is somebody, he is not something. 'Brad' is David's friend in the company. He knows a lot about the Kruger-Brent, limited. On this account, Brad must be a man considered very important in the company who can replace the position of David as a manager whenever necessary. 'Brad' is obviously not a weapon. But he is a man they can trust to care and to protect the company. Based on some point of similarity between Brad's ability as well as his knowledge about the company and a weapon as is generally understood, it is legitimate for the writer to metaphorically equate Brad with a weapon.

Seen from the elements of the metaphor, Brad is as 'the topic' being discussed, weapon is 'the image' given to Brad metaphorically. The topic and the image of the metaphor above explicitly stated. But the point of similarity (between Brad and the weapon) is not explicitly stated. Through observing the implied comparison between Brad, 'the topic' and weapon, 'the image', we can then conclude that Brad, the man they can trust to care and to protect the company is similar in function to weapon, that is a tool that can be used to care and to protect something or somebody. So, the point of similarity between Brad and the weapon can be established, namely as a protector. Metaphorical sentence 'Brad is our weapon' is not easily understood without examining the wider context. The intended meaning of the metaphor is uninferrable in isolation. That is why the reader must find out the hidden comparison through examining the whole context. Larson classifies such a metaphor as a live metaphor (Larson, 1984).

3) The future was clay, to be molded day by day, but the past was bedrock, immutable (p.347-348).

The clauses 'The future was clay' and 'the past was bedrock' in example above cannot have literal meanings. The two clauses are semantically unacceptable. Noun phrase 'the future' means the time that will come after the present or events that will happen then. It is clearly not 'clay'. The noun phrase 'the past' means the time that has gone by or things that happened in an earlier time. It is of course not 'bedrock'. That is why the clauses 'The future was clay' and 'the past was bedrock' must be metaphorically interpreted because they contain figurative meanings. The implied comparisons can be clearly identified by examining the elements: topic, image, and the point of similarity. 'The future' (topic) was referred to as 'clay' (image). In other words, 'the future' was compared to 'clay'. The point of similarity is clearly hinted at in the statement that 'clay' should be molded day by day. The reader is supposed to infer the intended meaning, it might be that in a sense we can form our future by our everyday actions.

Similar analysis is applicable to the parallel clause 'the past was bedrock'. 
Vol. 1, No. 1, Juli 2017, 103

Available Online at https://ejournal.warmadewa.ac.id/index.php/kulturistik DOI: http://dx.doi.org/10.22225/kulturistik.1.1.221

The comparison is between 'the past' and 'bedrock'. The point of similarity should be searched in the statement that bedrock was immutable. The intended meaning of the metaphor is more or less that we cannot do anything to change the past. All elements of the metaphors above are stated explicitly. The sentence is made up of two structurally parallel clauses and semantically both belong to the type of live metaphors.

4) How Ian Travis was really Jamie McGregor, and he had gotten Van der Merwes daughter pregnant. Margaret van der Merwe had fooled the whole town. "She doesn't look like the kind, does she".

"Still waters run deep, they say". "I wander how many other men in this town have dipped their wick in that well?" (p.114).

The sentence 'Still water runs deep' cannot be construed literally since the sentence is a saying. A saying is a short well-known phrase, expression or proverb (Hornby, $1995: 1045)$. This saying can be classified as a metaphor because it also shows an implied comparison. If examined carefully, the saying turns out to be an image of an implicit comparison but the topic is not explicitly stated. From the examination of the context, it can be inferred that the topic of the metaphor is Margaret van der Merwe. Then, on account of being unmarried but pregnant, she is depicted with the saying 'Still water runs deep' which means that a quiet or apparently calm person can have strong emotions or can be very dangerous. The point of similarity is to be construed in this context between Margaret and the image 'still water runs deep' is clear; Margaret's character is unpredictable, people had never thought that Margaret could have caused such a great commotion to people in the whole town. This saying is often used to give advice or warning that a seemingly calm person may be dangerous. Since it is a saying, it of course belongs to dead metaphor.

5) The bath in the Royal Suite was heaven. Jamie lay back in the hot water, soaking the tiredness out of his body, thinking back over the past incredible weeks (p.96).

'The bath in the Royal Suite was heaven' is certain to be a metaphor. A bath (or a bath-tub) is a long container to put water in and then for us to get into to wash our whole body; or the water in the bath-tub in which we sit wash our body. Heaven is a place believed to be the home of God and of virtuous people after death. The bath (in the sense of the bath-tub or the water in it) is associated with pleasure but it cannot be heaven. Thus, the sentence has to be figuratively interpreted.

The topic of the metaphor is 'the bath' which is compared to 'heaven'. The similarity is implicit. The context, however, leads us to infer that both are 'a place of happiness or comfort'. The metaphor should be classified as a live metaphor.

6) Jami and Margaret McGregor had been very good to him. And then there was Kate. He had cared for her since she was a baby. He had watched her grow up from a stubborn, dirty-faced tomboy to a lovely young woman. Her life was a photo album in his mind. He turned the pages and there was Kate at four, eight, ten, fourteen, twenty-one-vulnerable, unpredictable .... (212).

As we can see from the context of the metaphors, 'Kate's life' is implicitly compared to 'photo album'. The comparison is made on the basis of certain point 
Vol. 1, No. 1, Juli 2017, 104

Available Online at https://ejournal.warmadewa.ac.id/index.php/kulturistik DOI: http://dx.doi.org/10.22225/kulturistik.1.1.221

of similarity between 'Kate's life' and 'photo album'. The structure of the metaphor can also be traced by identifying its elements: topic, image, and point of similarity. 'Kate's life' is the 'topic' of the metaphor. Kate's life is then given the image a photo album. The comparison is continued in the following metaphor, 'He turned the pages and there was Kate'. Kate's progress of life is compared to a photo album. Each stage of her life is compared to each page in the album. To look back at her life is similar to turning over the pages of the album. This metaphor belongs to a live metaphor.

7) A wagonful of my relatives was leaving for Cape Town. We took you with us. You were out of your head most of the time. Each time you fell asleep, I was afraid you were not going to wake up again (p.62).

The sentence 'You were out of your head most of the time' is obviously difficult to understand literally. The difficulty is due to the semantic anomaly. The intended meaning must be different from its literal meaning. Since the sentence cannot be literally interpreted, then it must be metaphorically processed.

The topic is 'you' and the condition is described figuratively as being 'out of your head' as the image. 'Head' can be conceived as referring to 'consciousness or awareness', thus, someone losing his consciousness is arguably described as 'being out of his head'. Finally we can conclude that the implied similarity is one obtaining between the state in which the topic (you) and 'loss of consciousness'. In other words, the condition of losing consciousness is described as 'out of head'. The metaphor should, then be classified as a live metaphor.

8) When Jamie walked into Madam Agness that night, she said, "Have you heard the news, Jamie? Salomon van der Merwe blew his brains out an hour ago" (p.128).

We can observe clearly that the metaphorical sentence is 'Salomon van der Merwe blew his brains out an hour ago. What Salomon did is described as 'blowing his brains out'. From the context, we can discover that the intended meaning is to kill himself by shooting in the head. The context can be seen from the following sentences that immediately follow the quoted sentence above.

The funeral was held at the dreary, windswept cemetery outside down. Besides the burying crew, there were only two people in attendance: Margaret and Jamie McGregor (p.128).

This entailment shows that what is really meant by 'blew his brains out' is to kill himself. The implied comparison can be identified by examining the element of the metaphor. The topic of the metaphor is Salomon, and what he did is compared to 'blew his brains out', as the image. The implied similarity is implicit. From the context we can infer that the similarity is 'committing suicide'.

9) She did not need crumbs. She intended to have the whole cake. The question was: how was she going to get it? (p. 359).

At glance, both 'She did not need crumbs' and 'She intended to have the whole cake' could be interpreted literally but the context would not allow it. Subject 'She', in this case, refers to Eve, is not discussing about food. From the context it can be discovered that what she really means is that she wants to get not just a part of the property, 'crumbs' but the whole property, 'the whole cake' of her 
Vol. 1, No. 1, Juli 2017, 105

Available Online at https://ejournal.warmadewa.ac.id/index.php/kulturistik DOI: http://dx.doi.org/10.22225/kulturistik.1.1.221

grandmother. This can be supported by the following passage depicting her imagination.

She thought of Alexandra enjoying herself in the huge house on Fifth Avenue. My God, why couldn't Alexandra have burned to death? It had been so close! If she had died and Eve had been the only heiress, things would have been different. Her grandmother would not have dared disinherit her (p.353).

In the metaphorical sentence 'She intended to have the whole cake' we can identify the topic, image, and the point of the similarity. The comparison is not explicitly stated but the thing alluded to by Eve is the whole property of her grandmother. The image of the metaphor is 'the whole cake' which is figuratively compared to the 'whole property'. The point of similarity of this metaphor is not explicitly stated either, but it can be construed: both 'the cake' and 'the property' can be divided. 'Cake' is a kind of food that can be divided and allotted to different people, similarly with 'property'. The metaphor above is to be categorized as a live metaphor since for its comprehension it needs contextual analysis.

\section{CONCLUSSION}

From the whole analysis of the metaphors found in novel Master of the Game written by Sydney Sheldon, some conclusions are 1) the meaning of a metaphor taken out of its context frequently cannot be understood, 2) the structures of all metaphors consist of three elements, they are: topic, image, and point of similarity, whether they are implicitly or explicitly stated, 3) then understanding the meaning of a metaphor in terms of the implied comparison and the implied point of similarity is in need of relating the metaphor to its context, it is classified as a live metaphor, and 4) when a metaphor no longer refers to the comparison in the context of situation but can be directly understood as it has commonly been or (for us) is explained in the dictionaries, it is classified as a dead metaphor.

\section{REFERENCES}

Guo, S. (2013). Metaphor Studies from the Perspective of Critical Discourse Analysis: A Case Study of Business Acquisition. Theory and Practice in Language Studies, 3(3), 475-481. https://doi.org/10.4304/tpls.3.3.475-481

Hornby, A. (1995). Oxford advanced learners dictionary of current English. Oxford: Oxford University Press.

Lakoff, George and Johnson, M. (1984). Metaphors we live by. Chicago: University of Chicago Press.

Larson, M. L. (1984). Meaning-based translation. Lanham: Lanham University Press.

McArthur, T. (1992). The Oxford Companion to the English Language. New York: Oxford University Press.

Musolff, A. (2012). The study of metaphor as part of critical discourse analysis. Critical Discourse Studies, 9(3), 301-310. https://doi.org/http:// dx.doi.org/10.1080/17405904.2012.688300

Ortony, A. (1979). Metaphor and thought. Cambridge: Cambridge University Press.

Penninck, H. (2014). An analysis of metaphor used in political speeches responding to the financial crises of 1929 and 2008. Universiteit Gent.

Searle, J. R. (1985). Expression and meaning. Studies in the theory of speech 


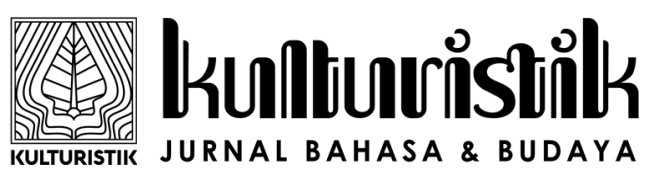

Vol. 1, No. 1, Juli 2017, 106

Available Online at https://ejournal.warmadewa.ac.id/index.php/kulturistik DOI: http://dx.doi.org/10.22225/kulturistik.1.1.221

acts. New York: Cambridge University Press.

Sudaryanto. (1993). Metode dan Aneka Teknik Analisis Bahasa. Yogyakarta: Duta Wacana University Press. 